\title{
Knowledge of diabetes among type 2 diabetes patients attending a primary health care clinic in Sri Lanka
}

D.P. Perera, ${ }^{7}$ R.E.E. De Silva ${ }^{2}$ and W.L.S.P. Perera ${ }^{3}$

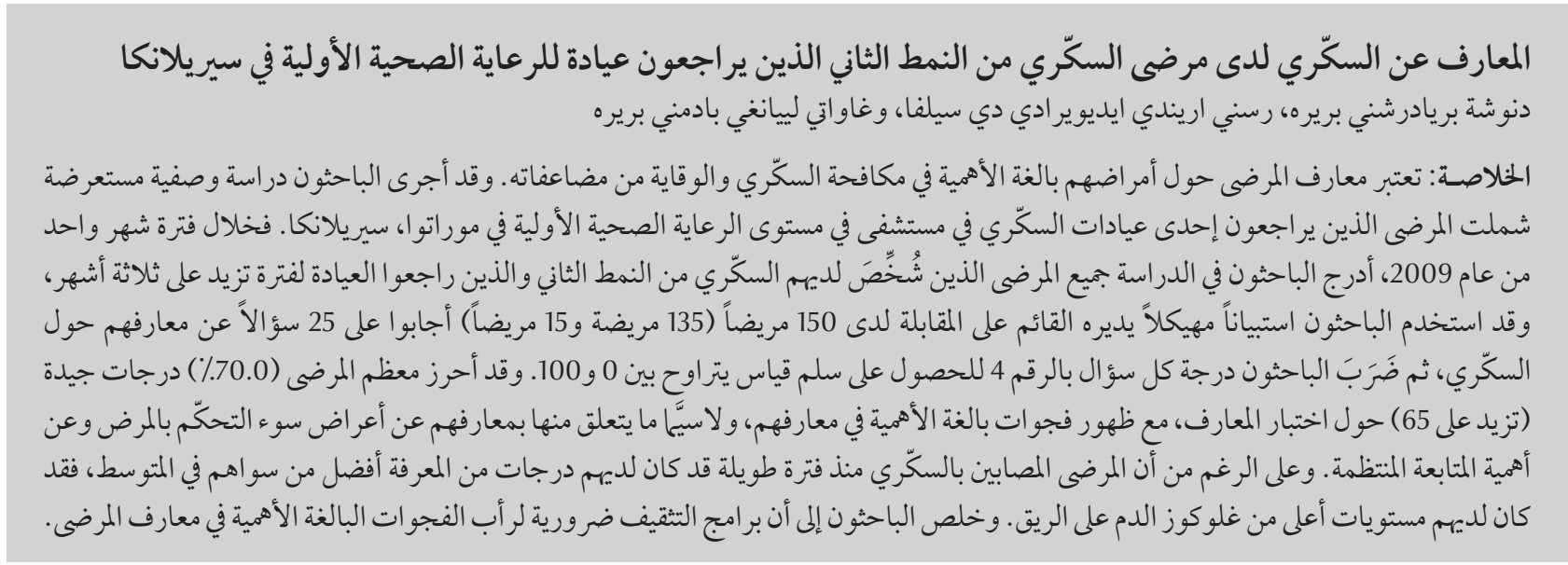

ABSTRACT Patients' knowledge about their illness is considered important in controlling diabetes and preventing complications. A descriptive, cross-sectional study was conducted among patients attending the diabetes clinic of a primary care level hospital in Moratuwa, Sri Lanka. During a 1-month period in 2009 all consenting patients diagnosed with type 2 diabetes who had been attending the clinic for more than 3 months were included in the study. Using an interviewer administered, structured questionnaire 150 patients (135 females, 15 males) answered 25 questions about diabetes knowledge (scored $\times 4$ to give score range $0-100)$. A majority of patients (70.0\%) had a good score (> 65) on the knowledge test but critical gaps in knowledge were revealed, especially regarding knowledge about symptoms of poor control and importance of regular follow-up. Although patients with longer duration of diabetes had higher mean knowledge scores, they also had higher fasting blood glucose levels. Education programmes are needed to address critical gaps in patients' knowledge.

\section{Connaissances sur le diabète chez des patients diabétiques de type 2 consultant dans un centre de soins de santé primaires au Ski Lanka}

RÉSUMÉ On considère que les connaissances des patients sur leur maladie sont importantes pour le contrôle du diabète et la prévention des complications. Une étude descriptive transversale a été menée auprès de patients consultant dans le service de prise en charge du diabète de l'hôpital de soins de santé primaires de Moratuwa (Sri Lanka). Pendant un mois en 2009, tous les patients consentants, à qui l'on avait diagnostiqué un diabète de type 2, et qui consultaient dans ce service depuis plus de trois mois, ont été recrutés dans l'étude. À l'aide d'un questionnaire structuré administré par un professionnel, 150 patients ( 135 femmes, 15 hommes) ont répondu à 25 questions sur leurs connaissances en matière de diabète (les scores ont été multipliés par quatre pour obtenir une échelle allant de 0 à 100). La majorité des patients (70,0\%) ont obtenu un bon score (> 65) au questionnaire, mais des lacunes majeures ont été constatées au niveau des connaissances, en particulier sur les symptômes d'un mauvais contrôle et l'importance d'un suivi régulier. Si les patients diabétiques depuis plus longtemps ont obtenu en moyenne de meilleurs scores de connaissances, leur glycémie à jeun était aussi plus élevée. Des programmes éducatifs sont requis pour s'attaquer aux importantes lacunes des patients au niveau des connaissances dans ce domaine.

'Department of Family Medicine, Faculty of Medicine, University of Kelaniya, Kelaniya, Sri Lanka (Correspondence to D.P. Perera: dinushapp@ yahoo.ca). ${ }^{2}$ Department of Family Medicine, Faculty of Medicine, University of Colombo, Colombo, Sri Lanka. ${ }^{3}$ Community Medicine Section, Ministry of Health, Colombo, Sri Lanka.

Received: 18/12/11; accepted: 13/03/12 


\section{Introduction}

The rapid increase in the prevalence of diabetes mellitus is a major public health concern worldwide. Elevated blood glucose levels and microvascular and cardiovascular complications substantially increase the morbidity and mortality associated with the disease [1]. The World Health Organization projects that by 2030 more than half of diabetics in the world will live in Asia, thereby creating a strain on the financial and medical resources of those countries [2]. The prevalence of diabetes is especially high in South Asia. A national survey in Sri Lanka in 2008 found that the prevalence of diabetes was $10.3 \%$ [3].

The importance of self-management skills in diabetes care has been stressed by the American Diabetes Association (ADA) [4]. Patients with diabetes, however, often lack sufficient knowledge about their disease and thus frequently have poor self-management skills $[5,6]$. Studies have indicated that poor health literacy may be a particularly important barrier to chronic disease care and good health outcomes [7]. It is imperative that the patients and key members of their families understand the basic facts about diabetes, such as the importance of maintaining good glycaemic control and the individual treatment schedules and preventive measures in the control of diabetes mellitus. This study attempted to assess the knowledge of diabetes and its complications among patients attending a primary care diabetes clinic in Sri Lanka.

\section{Methods}

\section{Study design and setting}

This was a descriptive, cross-sectional study conducted in the outpatient diabetes clinics of Moratuwa district hospital, a primary health care hospital in Moratuwa city, in the Western province of Sri Lanka. This hospital provides services free of charge, and the target patient population includes people living in close proximity to the hospital. Patients usually attend the clinic once a month. All patients with diabetes are treated by the primary care medical practitioners of the hospital. The usual care consists of starting with oral hypoglycaemic agents with assessment of control and combining oral hypoglycaemics as necessary. Insulin may be added as necessary for adequate control. Patients attend the clinic once a month and drugs are issued free of charge as available. Patients have to buy unavailable drugs at their own cost. Fasting blood sugar is determined once a month at the hospital laboratory.

\section{Sample and setting}

During the 1-month period 1 July 2009 to 1 August 2009 all consenting patients aged $18+$ years diagnosed with type 2 diabetes who had been attending the clinic for more than 3 months were included in the study. Diabetes was defined as fasting plasma glucose (FPG) $>7 \mathrm{mmol} / \mathrm{L}$ or random plasma glucose $>11.1 \mathrm{mmol} / \mathrm{L}$, once if symptomatic or repeated if asymptomatic A single month was selected as the study period as the same patients come to the clinic once a month for their follow-up visits and to obtain their medication. A total of 150 patients with type 2 diabetes were entered in the study. All patients were provided with an information sheet, given a verbal explanation of the nature of the study by the researchers and their verbal consent was obtained prior to enrolment.

\section{Data collection}

Participants were interviewed by the researchers using a validated, structured questionnaire. An extensive literature search was conducted in formulating the questionnaire and a number of studies based on questionnaires with similar questions were used [8-10]. The questionnaire was first drafted by the 3 investigators, 2 family physicians and a community physician. The subject content was scrutinized and approved by a specialist in endocrinology. The questionnaire was finalized after engaging in several focus group discussions utilizing a Delphi technique among the researchers, doctors and nurses caring for the patients and a sample of the pilot group of patients. The questionnaire was piloted on 20 patients who regularly attended the diabetic clinic and attended the hospital primary care unit for health care visits other than to attend the diabetic clinic. These 20 patients were excluded from the study.

The questionnaire was formulated in all 3 official languages Sinhala, Tamil and English, checked by a professional translator, and was administered by the principal investigator. The questionnaire consisted of 2 sections: demographic details and diabetes knowledge assessment. The section on diabetes knowledge consisted of 25 questions about the symptoms of diabetes, symptoms of hypoglycaemia and hyperglycaemia, optimal control targets, micro- and macrovascular complications and lifestyle modifications. Each item had yes/no/don't know response key. A scoring system was developed, whereby the total number of correct responses for the knowledge section was calculated for each respondent and multiplied by 4 to give a score out of 100. Each correct answer was given a mark and the total mark calculated out of 100. Knowledge was graded as very good (score $>75$ ), good (65-75), average (50-65), poor $(40-50)$ or very poor $(<40)$. Each questionnaire took approximately $5-8$ minutes to administer. Data were also obtained regarding recent glycaemic control as part of the routine screening at the clinic.

\section{Data analysis}

The data were analysed using SPSS, version 16 statistical package and Student $t$-test was used to compare group means. 


\section{Results}

\section{Demographic data}

The mean age of the participants was 56.3 years (SD 10.1), range 30-71 years. The majority of the 150 respondents were married (96.0\%), dependent on others for their income (94.0\%), female (90.0\%) and living within $5 \mathrm{~km}$ of the hospital (98.0\%). The illiteracy rate was $8.0 \%$, while $42.6 \%$ had received primary education and $49.3 \%$ secondary education. A majority of respondents (83.3\%) had a family income below rupees (Rs) 10000 per month (US\$ 90 approximately) (Table 1).

\section{Clinical data}

Almost half of the participants (49.3\%) had been diagnosed with type 2 diabetes for $>5$ years, $36.7 \%$ for $1-5$ years and $14.0 \%$ for $<1$ year. The mean value of the latest fasting blood sugar (FBS) test was $163 \mathrm{mg} / \mathrm{dL}$.

\section{Knowledge about diabetes}

The overall mean knowledge score of the participants was $68.1 \%$ (SD 9.0\%). A majority of participants $(70.0 \%)$ had a good or very good score $(>65)$ on the knowledge test, while $26.76 \%$ had a very good score (> 75) (Table 2). A high proportion of the participants (44.0\%) believed that diabetes could be cured (Table 3). More than $90 \%$ of patients could not recognize the symptoms of hypo/hyperglycaemia and only around $60 \%$ knew the normal range of fasting blood sugar, that blood sugar should be measured regularly to assess control, that regular exercise is helpful to control diabetes and that it is important to control the diet in addition to taking medication in the management of diabetes. Only twothirds of the sample (68.0\%) knew that feet should be examined regularly for any lesions and even fewer (50.0\%) knew the importance of assessing vision annually.

\begin{tabular}{|c|c|c|}
\hline Variable & $\begin{array}{c}\text { No. of } \\
\text { patients }\end{array}$ & $\begin{array}{c}\% \\
(n=150)\end{array}$ \\
\hline \multicolumn{3}{|l|}{ Age (years) } \\
\hline$<40$ & 15 & 10.0 \\
\hline $40-60$ & 71 & 47.3 \\
\hline$>60$ & 64 & 42.6 \\
\hline \multicolumn{3}{|l|}{ Sex } \\
\hline Male & 15 & 10.0 \\
\hline Female & 135 & 90.0 \\
\hline \multicolumn{3}{|l|}{ Education level } \\
\hline Illiterate & 12 & 8.0 \\
\hline Primary & 64 & 42.7 \\
\hline Secondary & 74 & 49.3 \\
\hline \multicolumn{3}{|l|}{ Occupation } \\
\hline Employed & 9 & 6.0 \\
\hline Not employed & 141 & 94.0 \\
\hline \multicolumn{3}{|l|}{ Marital status } \\
\hline Single & 6 & 4.0 \\
\hline Married & 144 & 96.0 \\
\hline \multicolumn{3}{|l|}{ Income per month (Rs) } \\
\hline$<5000$ & 47 & 31.3 \\
\hline 5000-10000 & 78 & 52.0 \\
\hline $10000-25000$ & 23 & 15.3 \\
\hline$>25000$ & 2 & 1.3 \\
\hline \multicolumn{3}{|l|}{ Own income } \\
\hline Have an own income & 9 & 6.0 \\
\hline No own income (dependant) & 141 & 94.0 \\
\hline \multicolumn{3}{|l|}{ Family } \\
\hline Living alone & 14 & 9.3 \\
\hline Living with family & 136 & 90.6 \\
\hline
\end{tabular}

The mean knowledge scores among those who had had the disease for a longer duration was higher than those who had the disease for a shorter duration of time and this difference was statistically significant (Student t-test, $P<0.001)$ (Table 4). However, this did not translate into better control of their blood sugar levels, as those who had had diabetes for the longest also had the highest mean FBS level. There was no significant difference in mean knowledge score among those with illiterate or primary level of education [1.57 (SD 0.72)] compared with those with secondary education [1.53 (SD 0.86)].

\section{Discussion}

It is essential that diabetic patients should possess good knowledge about their illness in order to improve their self-management skills and thereby prevent complications. Research has found that less frequent self-care behaviours were evident among particularly high-risk diabetic patients with lower educational levels [11]. Another study revealed that among primary care patients with type 2 diabetes, poor health literacy was independently associated with worse glycaemic control and higher rates of retinopathy $[12,13]$. 


Table 2 Diabetes knowledge scores at different cut-offs among the study group of
patients
\begin{tabular}{lccc}
\hline Knowledge score & Grade & No. & $\%$ \\
$\geq 75$ & Very good & 40 & 26.7 \\
$65-74$ & Good & 65 & 43.3 \\
$50-64$ & Average & 33 & 22.0 \\
$40-49$ & Poor & 12 & 8.0 \\
$<40$ & Very poor & 0 & 0.0 \\
\hline
\end{tabular}

There is growing evidence highlighting the importance of self-management skills in diabetes, and the ADA has endorsed self-management education as the process of providing the person with diabetes with the knowledge and skills that are necessary for self-care, management of crises and implementation of lifestyle changes [14].

It was encouraging that in our study a majority of participants (70.0\%) had good or very good scores $(>65)$ on the knowledge test. A similar study carried out in Pakistan revealed that only $13.6 \%$ of the participants had a good knowledge score $(>60)$ [15].

Many of our findings in the various knowledge areas were consistent with the findings of other studies, such as the knowledge that diabetes can be inherited. Even in other studies, in which the overall diabetes knowledge did not appear to be adequate, participants had stated that diabetes was an inheritable disease [16]. Despite the fact that the majority of patients had had diabetes for more than 5 years a major proportion (44.0\%) of the participants thought that diabetes could be cured. This agrees with evidence from other studies which indicated that a high proportion of patients in a study in Gujarat state in India (38.2\%) believed that diabetes could be cured [17].

Although the overall mean knowledge score $(68.1 \%)$ was satisfactory, it is noteworthy that only $58.0 \%$ knew the normal range of fasting blood sugar and $60.7 \%$ knew that blood sugar should be measured regularly to assess control. This is also consistent with other studies done in the South Asian region where the majority of patients did not know the ideal blood glucose target

\begin{tabular}{|c|c|}
\hline Item & $\%$ correct \\
\hline Know that diabetes could be inherited & 92.7 \\
\hline Know that chronic complications could occur & 90.0 \\
\hline $\begin{array}{l}\text { Know that diabetes is associated with a lack of effective insulin in } \\
\text { the body }\end{array}$ & 90.0 \\
\hline Know that regular examination of feet should be done & 68.0 \\
\hline $\begin{array}{l}\text { Know that blood sugar should be measured regularly to assess } \\
\text { control }\end{array}$ & 60.7 \\
\hline Know that regular exercise is helpful to control diabetes & 60.0 \\
\hline $\begin{array}{l}\text { Know the importance of dietary regulation in addition to } \\
\text { medication }\end{array}$ & 60.0 \\
\hline Aware of normal range of fasting blood sugar & 58.0 \\
\hline Know that diabetes cannot be cured & 56.0 \\
\hline Know that annual eye examination should be done & 50.0 \\
\hline Able to recognize symptoms of hypoglycaemia & 8.0 \\
\hline Able to recognize symptoms of hyperglycaemia & 9.3 \\
\hline
\end{tabular}

levels $[10,15,18]$. A high proportion of our participants (40.0\%) did not know that regular exercise is helpful to control type 2 diabetes. It is also noteworthy that only $60.0 \%$ knew that it is important to control the diet in addition to taking medication for diabetes. In a similar study conducted in Pakistan it was reported that only $28 \%$ of diabetic thought dietary modification was important while only $6 \%$ believed that weight loss was important in the management of diabetes [16].

It is alarming to note that although the great majority of patients knew that chronic complications do occur (90.0\%), most patients were unaware of the symptoms of hyperglycaemia or hypoglycaemia (90.0\%). Only 68.0\% of patients knew that feet should be examined regularly for any lesions. A study carried out in Pakistan found that knowledge about diabetic foot care was poor in $30.7 \%$ of diabetics [19]. Also concerning is that, even though diabetes is currently the leading cause of new cases of blindness in adults in many industrialized countries and an increasingly more frequent cause of blindness elsewhere [20], only half of our study participants knew the importance of assessing vision annually to prevent diabetic retinopathy. Patients' knowledge about diabetic eye disease was also poor in other studies carried out in the South Asian region. Hoque et al. in Bangladesh, for example, found that only $4.9 \%$ of their study participants were aware about diabetic eye disease [9].

There were some limitations to our study that should be noted. The percentage of female patients was $90.0 \%$. This is probably due to the fact that the clinic was conducted on weekdays when more male patients might be at work compared with the female participants who were mostly dependent, married females. This study was a small study conducted at a diabetes clinic caring for approximately $300 \mathrm{pa}-$ tients per month. Therefore the good knowledge reported here may not be 


\begin{tabular}{|c|c|c|c|c|}
\hline \multirow[t]{2}{*}{ Duration of diabetes (years) } & \multirow[t]{2}{*}{$\begin{array}{c}\text { No. of } \\
\text { patients }\end{array}$} & \multirow[t]{2}{*}{$\%$} & $\begin{array}{l}\text { Overall knowledge } \\
\text { score }\end{array}$ & $\begin{array}{l}\text { Fasting blood sugar level } \\
(\mathrm{mg} / \mathrm{dL})\end{array}$ \\
\hline & & & Mean (SD) & Mean (SD) \\
\hline$<1$ & 21 & 14.0 & $58.0(2.3)$ & $110(12.2)$ \\
\hline $1-5$ & 55 & 36.7 & $62.6(6.8)$ & $164(7.5)$ \\
\hline$>5$ & 74 & 49.3 & $75.0(5.3)$ & $176(7.6)$ \\
\hline Total & 150 & 100.0 & $68.1(9.0)$ & $163(23.6)$ \\
\hline
\end{tabular}

$S D=$ standard deviation.

representative of the community as there may be diabetics who do not visit the hospital.

\section{Conclusion}

In conclusion, although overall knowledge about diabetes among our patients was adequate there were critical gaps in knowledge. In particular, knowledge about the management of diabetes and diabetic complications was poor. This study has helped identify areas where there were gaps in patient knowledge. The findings could be used in an integrated programme to improve patient self-management. Since this study was conducted at a single community health care centre the results do not reflect the knowledge of the general population and further studies are required particularly in different settings to identify patient educational needs and methods to improve selfmanagement of diabetes.

Competing interests: None declared

\section{References}

1. American Diabetes Association. Implications of the United Kingdom prospective diabetes study. Diabetes Care, 2003, 26(Suppl. 1):S28-S32.

2. Diabetes. Fact sheet No. 312. World Health Organization [online factsheet] (http://www.who.int/mediacentre/factsheets/ fs312/en/index.html, accessed 13 January 2013).

3. Katulanda P et al. Prevalence and projections of diabetes and pre-diabetes in adults in Sri Lanka-Sri Lanka Diabetes, Cardiovascular Study (SLDCS). Diabetic Medicine, 2008, 25:1062-1069.

4. American Diabetes Association. Standards of medical care in diabetes Diabetes Care, 2005, 28(Suppl. 1):s4-s36.

5. West JD, Goldberg KL. Diabetes self-care knowledge among outpatients at a Veterans Affairs medical centre. American Journal of Health-System Pharmacy, 2002, 59:849-852.

6. Via PS, Salyer J. Psychosocial self-efficacy and personal characteristics of veterans attending a diabetes education program. Diabetes Educator, 1999, 25:727-737.

7. Health literacy: report of the Council on Scientific Affairs. Ad Hoc Committee on Health Literacy for the Council on Scientific Affairs, American Medical Association. Journal of the American Medical Association, 1999, 281:552-557

8. Baradaran HR et al. Baradaran HR et a I A controlled trial of the effectiveness of a diabetes education programme in a multiethnic community in Glasgow. BMC Public Health, 2006, 6:134.

9. Hoque MA et al. Knowledge of diabetic complications in a diabetic population. Journal of Medicine, 2009, 10:90-93.

10. Gul N. Knowledge, attitudes and practices of type 2 diabetic patients. Journal of Ayub Medical College, Abbottabad, 2010, 22:128-131.

11. Karter AJ et al. Educational disparities in health behaviors among patients with diabetes: the Translating Research Into
Action for Diabetes (TRIAD) Study. BMC Public Health, 2007, 7:308.

12. Schillinger $\mathrm{D}$ et al. Association of health literacy with diabetes outcomes. Journal of the American Medical Association, 2002, 288:475-482.

13. Heisler $\mathrm{M}$ et al. The relationship between knowledge of recent $\mathrm{HbAlc}$ values and diabetes care understanding and self-management. Diabetes Care, 2005, 28:816-822.

14. Clement S. Diabetes self-management education. Diabetes Care, 1995, 18:1204-1214.

15. Rafique G, Azam SI, White F. Diabetes knowledge, beliefs and practices among people with diabetes attending a university hospital in Karachi, Pakistan. Eastern Mediterranean Health Journal, 2006, 12:590-598.

16. Hashmi NR, Manzoor I, Daud S. Diabetes mellitus: awareness among individuals attending out patient department of Ghurki trust teaching hospital. Professional Medical Journal, 2008, 15:96-100.

17. Shah VN, Kamdar PK, Shah N. Assessing the knowledge, attitudes and practice of type 2 diabetes among patients of Saurashtra region, Gujarat. International Journal of Diabetes in Developing Countries, 2009, 29:118-122.

18. Kapur A et al. Diabetes care in India ---Patients perceptions, attitudes and practices. International Journal of Diabetes in Developing Countries, 1997, 17:5-14.

19. Hasnain S, Sheikh NH. Knowledge and practices regarding foot care in diabetic patients visiting diabetic clinic in Jinnah Hospital, Lahore. Journal of the Pakistan Medical Association, 2009, 59:687-690.

20. Prevention of blindness from diabetes mellitus. Report of a WHO consultation in Geneva, Switzerland, 9-11 November 2005. Geneva, World Health Organization, 2006. 